\title{
Effects of processing, particle size and moisturizing of sorghum-based feeds on pellet quality and broiler production
}

\author{
Patrícia Garcia da Silva', Luana Martins Schaly Oliveira', Nayanne Rodrigues de Oliveira', \\ Fábio Ataides de Moura Júnior ${ }^{1}$, Maura Regina Sousa Silva ${ }^{1}$, Deibity Alves Cordeiro', \\ Cibele Silva Minafra', and Fabiana Ramos dos Santos ${ }^{1, *}$
}

\begin{abstract}
* Corresponding Author: Fabiana Ramos dos Santos Tel: +55-64-9-9618-0638,

E-mail: Fabiana.santos@ifgoiano.com.br
\end{abstract}

'Instituto Federal de Educação, Ciência e Tecnologia Goiano, Rio Verde, Goiás 75901-970, Brazil

ORCID

Patrícia Garcia da Silva

https://orcid.org/0000-0003-4355-1198

Luana Martins Schaly Oliveira

https://orcid.org/0000-0001-7381-0109

Nayanne Rodrigues de Oliveira

https://orcid. org/0000-0003-2173-185X

Fábio Ataides de Moura Júnior

https://orcid.org/0000-0002-5646-458X

Maura Regina Sousa Silva

https://orcid.org/0000-0001-7195-0001

Deibity Alves Cordeiro

https://orcid.org/0000-0002-4948-8559

Cibele Silva Minafra

https://orcid.org/0000-0002-4286-2982

Fabiana Ramos dos Santos

https://orcid.org/0000-0002-0287-1681

Submitted Jun 22, 2017; Revised Jul 13, 2017; Accepted Sept 12, 2017
Objective: This study aimed to assess the effect of pelleted and expanded sorghum-based feeds prepared with different moisture levels and particle size of ingredients on metabolizable energy, ileal digestibility of amino acids and broiler performance.

Methods: The experiment was performed with 720 male broiler chicks of the Cobb strain, with treatments of six replications, with 15 birds each; they were arranged in a completely randomized design and $2 \times 2 \times 2$ factorial scheme (pelleted or expanded feed processing, $0.8 \%$ or $1.6 \%$ moisture addition in the mixer, and particle size of 650 or 850 microns).

Results: Higher pellet quality (pellets, $\%$ and pellet durability index [PDI]) was obtained in expanded diets and inclusion of $1.6 \%$ moisture. The particle size of 850 microns increased the PDI of final diet. All studied treatments had no significant effect on weight gain and broiler carcass and cut yields. Lower feed conversion occurred for birds fed pelleted feed at $42 \mathrm{~d}$. The highest apparent metabolizable energy (AME) and apparent metabolizable energy corrected to zero nitrogen balance (AMEn) values of feed in the initial rearing phase (10 to 13 days) were observed in birds fed pelleted feed or for feed prepared with $1.6 \%$ moisture. The highest ileal digestibility coefficients of amino acids were obtained with the consumption of pelleted feed prepared with a particle size of 650 microns and $1.6 \%$ moisture.

Conclusion: Pelleted feed prepared with a milling particle size of 650 microns and 1.6\% moisture provided increased ileal digestibility of amino acids and AMEn in the starter period. However, the expanded feed improved pellet quality and feed conversion of broilers at 42 days of age. We conclude that factors such as moisture, particle size and processing affect the pellet quality, and therefore should be considered when attempting to optimize broiler performance.

Keywords: Amino Acid; Expanded; Moisture; Particle Size; Performance

\section{INTRODUCTION}

Studies show that sorghum can be an alternative energy source because of its nutritional composition similar to corn, lower cost and increased grain availability in the domestic market. But, published data on the influence of conditioning temperature on the performance and nutrient utilisation of broilers fed maize- and sorghum-based diets are limited [1].

The physical form and thermal treatment of feeds can cause improvements in the use of nutrients due to superior digestibility and increased absorption [2]. In addition, broilers fed pelleted diets perform better compared to mash diets due to facility of eating $g$ attributed ease of seizure of the ration, in addition to reducing food waste and energy expenditure during consumption [3]. However, the benefits of processed feeds on birds' performance depend on pellet quality, i.e., a high proportion of intact pellets and low concentration of fine or disintegrated granules.

Size, shape and structure of particles influence digestibility and dispersion of nutrients, alter 
feed density, pellet quality, fluidity of ingredients within the mixing system, transportation and supply to feeders, and increase the energy consumed in milling [4]. Chewning et al [5] also described that smaller particles optimize the starch gelatinization process, favoring the digestibility of food. Another limiting factor in the quality of processed feeds is the amount of water added during preparation [6]. Both water added to the mixer and that added as steam during conditioning enhance particle adhesion, improving pellet quality, as documented by Buchanan and Moritz [7].

Therefore, the aim of this study was to assess the effect of pelleted and pelleted-expanded sorghum-based feeds prepared with different moisture addition levels $(0.8 \%$ and $1.6 \%$ of water addition to the mixer) and two different particle sizes of ingredients (650 and 850 microns) on the performance, metabolizable energy of feed and ileal digestibility of amino acids of broilers.

\section{MATERIALS AND METHODS}

The experiment was conducted at the Federal Institute of Goiás State (Instituto Federal Goiano), Rio Verde, GO, Brazil. We used 720 day-old male broiler chicks of the Cobb strain, with initial average weight of $38 \pm 1.8 \mathrm{~g}$. The experimental period was 42 days. The research project was approved by the ethics committee on animal research of the institution under protocol number 009/ 2014.

The experimental design was completely randomized in a $2 \times$ $2 \times 2$ factorial scheme (pelleted or expanded-pelleted feed processing; $0.8 \%$ or $1.6 \%$ moisture addition in the mixer; particle size of ingredients of 650 or 850 microns) with six replications of 15 birds in each cage.

Chicks were housed in batteries with four metal cages each $(0.90 \times 0.60 \times 0.40 \mathrm{~m})$. These cages were equipped with trough feeders and drinkers, a 100-W lamp for heating, and metal trays for excreta collection. The birds remained under constant lighting (natural and artificial) with temperature check twice a day and curtain handling. The average temperature registered during the experiment was $28^{\circ} \mathrm{C} \pm 2.4^{\circ} \mathrm{C}$, with a minimum of $19^{\circ} \mathrm{C}$ and a maximum of $39^{\circ} \mathrm{C}$. Water and feed were provided ad libitum throughout the experimental period.

\section{Experimental diets}

The experimental diets were formulated based on sorghum and soybean meal to meet the nutritional demands for the initial ( 1 to 21 days), growth (22 to 35 days) and final (36 to 42 days) phases, according to the nutritional industry recommendations (Table 1).

The experimental feeds were produced using an integrated broiler feed mill. The cereal milling method consisted of the use of co-milling using a hammer mill and the particle size was obtained by setting $5.0 \mathrm{~mm}$ for particles of 650 microns and $6.5 \mathrm{~mm}$ for 850 microns. Two different processes (pelleted and pelletedexpanded) were used to pelletize and expand the feeds, which consisted of the use of a Kahl expander and a Buhler pelletizer.
Table 1. Centesimal composition and calculated nutritional levels of the experimental feeds in the initial, growth and final phases

\begin{tabular}{|c|c|c|c|}
\hline \multirow{2}{*}{ Item } & \multicolumn{3}{|c|}{ Natural matter (\%) } \\
\hline & Initial & Growth & Final \\
\hline \multicolumn{4}{|l|}{ Ingredients } \\
\hline Sorghum & 53.00 & 56.93 & 59.65 \\
\hline Soybean meal (46\%) & 37.20 & 33.89 & 30.90 \\
\hline Soybean oil & 4.51 & 5.16 & 5.89 \\
\hline Dicalcium phosphate & 1.54 & 1.26 & 1.06 \\
\hline Limestone & 1.17 & 1.02 & 0.91 \\
\hline Granulated salt & 0.51 & 0.46 & 0.44 \\
\hline Kaolin & 0.70 & - & - \\
\hline Methionine & 0.41 & 0.38 & 0.33 \\
\hline Lysine & 0.34 & 0.33 & 0.33 \\
\hline Vitamin-mineral premix ${ }^{11}$ & 1.30 & 1.30 & 1.30 \\
\hline Anti-salmonella & 0.48 & 0.47 & 0.45 \\
\hline Threonine & 0.09 & 0.08 & 0.07 \\
\hline Choline chloride & 0.04 & 0.03 & 0.02 \\
\hline Total & 100.01 & 100.01 & 100.00 \\
\hline \multicolumn{4}{|l|}{ Calculated levels } \\
\hline Metabolizable energy (kcal/kg) & 2,989 & 3,094 & 3,175 \\
\hline Crude protein (\%) & 22.21 & 21.02 & 19.88 \\
\hline Dietary digestible lysine (\%) & 1.21 & 1.12 & 1.06 \\
\hline Dietary digestible methionine (\%) & 0.48 & 0.55 & 0.51 \\
\hline Dietary digestible threonine (\%) & 0.65 & 0.65 & 0.65 \\
\hline Dietary digestible tryptophan & 0.19 & 0.19 & 0.19 \\
\hline Calcium (\%) & 1.01 & 0.87 & 0.76 \\
\hline Sodium (\%) & 0.22 & 0.20 & 0.19 \\
\hline
\end{tabular}

${ }^{1)}$ Vitamin-mineral premix (nutritional levels per kilo of product): calcium 1.0\%; sodium $3.9 \%$; potassium $0.01 \%$; chlorine $0.02 \%$; mineral matter $56.96 \%$; copper $5,993.33$ ppm; iron 14,979.00 ppm; manganese 34,437.70 ppm; zinc 29,970.41 ppm; iodine 599.37 ppm; selenium 199.19 ppm; vitamin $A_{3}, 136.00$ IU; vitamin $D_{3} 963.20$ IU; vitamin E 17,360.00 ppm; vitamin K 729.26 ppm; vitamin $B_{1} 824.32$ ppm; vitamin $B_{2}$ $3,225.60$ ppm; vitamin $B_{6} 1,395.36$ ppm; vitamin $B_{12} 11.87$ ppm; folic acid 1,032.08 ppm; nicotinic acid 10,363.00 ppm; pantothenic acid 5,241.60 ppm; biotin 75.00 ppm; monensin 110.00 ppm.

The processing temperature was $82^{\circ} \mathrm{C}$ for 34 seconds in the conditioner for the pelletizer and $130^{\circ} \mathrm{C}$ for 11 seconds for the expander, producing pellet size of $4.00 \mathrm{~mm}$. In the feeds of each rearing phase, the pellet percentage was measured by sieving the feed and separating the thin from the thick portion using a perforated container subjected to agitation [8]. In order to assess the durability index, $500 \mathrm{~g}$ of intact pellets was placed in a box rotating at $50 \mathrm{rpm}$ for 10 minutes. After that, the sample was sifted through a sieve of $3.0 \mathrm{~mm}$ diameter and the pellets which remained in the sieve were considered whole $[9,10]$.

\section{Performance assessment}

The animal performance variables assessed were body weight (BW), feed intake (FI) and feed conversion (FC) at 21 and 42 days of age. The number of dead birds was recorded at intervals as a criterion for correction of consumption and FC.

At 42 days of age, two birds with similar BW to that plot were slaughtered after 12 hour fasting to check the yield in percentage of carcass and cuts: breast, thigh, drumstick and abdominal fat. 
Carcass yield was calculated in relation to the live weight before slaughtering, and the cut yield depending on the hot carcass weight.

\section{Nutritional utilization assessment}

The total excreta collection method was used to determine the apparent metabolizable energy (AME) and the apparent metabolizable energy corrected to zero nitrogen balance (AMEn) of the experimental feeds from 10 to 13 and from 27 to 30 days of age. The AME and AMEn values were calculated using the equations described by Matterson et al [11].

$$
\begin{aligned}
& \text { AME }(\mathrm{kcal} / \mathrm{kg})=\frac{\text { GEing }- \text { GEexc }}{\mathrm{DM} \text { ing }} \\
& \text { AMEn }(\mathrm{kcal} / \mathrm{kg})=\frac{\text { GEing }- \text { GEexc }-8.22 \times \mathrm{NB}}{\mathrm{DM} \text { ing }} \\
& \text { GEing = Ingested gross energy (kcal); } \\
& \text { GEexc = Extracted gross energy (kcal); } \\
& \text { DM ing = Dry matter ingested (g) } \\
& \text { NB = Nitrogen balance, ingested nitrogen }
\end{aligned}
$$

Samples of ileal digesta were collected at $21 \mathrm{~d}$ post hatching to determine the digestibility of amino acids as described by Sakomura and Rostagno [12]. Kaolin, a source of silica, was added to the feed of the initial rearing phase, at a level of $0.70 \%$, in order to increase the levels of acid-insoluble ash, which was used as indigestible indicator [13]. At 21 days of age, five birds per repetition were slaughtered by cervical dislocation. The ileum was exposed by abdominal incision, a segment of $30 \mathrm{~cm}$ ending at $4.0 \mathrm{~cm}$ from the ileocecal junction was removed, and its content collected.

Samples of the experimental feed, ileal digesta and excreta were sent to the Animal Nutrition Laboratory of the IFGoiano, Rio Verde, Goiás, Brazil, to determine the content of dry matter (INCTCA G-003/1 method) and crude protein (INCT-CA N-001/1 method), according to the standard techniques of the Brazilian National Institute of Science and Technology in Animal Science (INCT-CA; [14]). The GE values were determined using an IKA C5001 adiabatic calorimeter. To avoid amino acid losses, the digesta were dried in a lyophilizer at $-53^{\circ} \mathrm{C}$ during 72 hours. The total amino acids of feeds and digesta were determined using high-performance liquid chromatography. The acid-insoluble ash was determined according to the method described by Santos et al [15]. From the laboratory results, the coefficients of ileal digestibility of amino acids were determined, as described by Sakomura and Rostagno [12].

\section{Data analysis}

The data underwent analysis of variance using the SISVAR 5.0 software [16] and the means were compared by the Tukey test at $1 \%$ and $5 \%$ probability.

\section{RESULTS}

The expanded feeds of the initial, growing and final phases had higher pellet percentage by an average $11.6 \%$ compared with pelleted feeds. The inclusion of $1.6 \%$ moisture in the experimental feeds raised the pellet percentage by $9 \%$. The expansion of the feeds of the different periods increased the pellet durability index (PDI) by $13.47 \%$ in relation to the pelleted feeds, while the addition of $1.6 \%$ water in the growth and final periods increased the PDI by $8.37 \%$. An effect of granulometry of the ingredients on PDI was observed only for the final phase feed. The particle size of 850 microns increased the PDI of this feed (Table 2).

Table 3 shows the values of AME and AMEn. The results demonstrate the lack of effect of the processing methods, particle size and moisture levels during chicken growth phase (27 to 30 days). However, throughout the initial rearing phase (10 to 13 days), the birds fed pelleted feeds, as well as those with 1.6\% moisture addition, presented higher values of both AME and AMEn.

The moisture levels had significant interaction with processing methods in the initial rearing phase (10 to 13 days) and with particle size during the growth phase (27 to 30 days). The statistical breakdown of interactions, shown in Table 4, reveals that AME and AMEn values did not differ between the moisture levels $(0.8 \%$ and $1.6 \%$ ) in the initial rearing phase for broilers given expanded feeds. However, birds fed pelleted feeds at 1.6\% moisture presented AME and AMEn values higher than those given the expanded feeds. During the growth phase, feeds produced with a particle size of 650 microns and 1.6\% moisture resulted in improved energy use (AME and AMEn).

There were no differences in the feeds prepared with a particle size of 850 microns considering the different moisture levels.

Assessing the main effects, we observed higher values of ileal digestibility coefficients in sorghum-based pelleted feeds when compared to the expanded feeds for the amino acids lysine and glycine (Table 5). The birds fed processed feeds with 650 micron particle size showed higher CID for serine, arginine, lysine and tyrosine. When assessing the effects of moisture addition to the mixer, we observed that the amino acids lysine methionine, cystine, met+cys, glycine, histidine, isoleucine, arginine, and tyrosine showed higher CID with $1.6 \%$ moisture addition (Table 5).

We observed interaction between milling particle size and moisture for the amino acids threonine, cystine and glycine. The statistical breakdown of the interaction of particle size and moisture level (Table 6) showed that the highest CID values were obtained with consumption of feed prepared with particle size of $650 \mathrm{mi}$ crons and 1.6\% moisture level. Conversely, there was no effect on that variable of moisture for the feeds prepared with particle size of 850 microns.

There were no significant effects on FI and weigh gain of the birds at 21 and 42 days of age. At 42 days of age, we observed higher FC for birds fed pelleted feeds compared to those that consumed expanded feeds (Table 7). 
Table 2. Percentage of pellet (\%) and pellet durability index (PDI, \%) of the experimental feeds in the initial, growth and final phases ${ }^{1)}$

\begin{tabular}{|c|c|c|c|c|c|c|}
\hline \multirow{2}{*}{ Item } & \multicolumn{2}{|c|}{ Initial } & \multicolumn{2}{|c|}{ Growth } & \multicolumn{2}{|c|}{ Final } \\
\hline & Pellet (\%) & PDI (\%) & Pellet (\%) & PDI (\%) & Pellet (\%) & PDI (\%) \\
\hline Expanded & $92.79^{a}$ & $85.07^{\mathrm{a}}$ & $89.88^{a}$ & $81.78^{a}$ & $93.05^{a}$ & $81.16^{a}$ \\
\hline Pelleted & $84.88^{b}$ & $72.05^{b}$ & $81.18^{b}$ & $72.54^{b}$ & $81.00^{b}$ & $73.81^{b}$ \\
\hline SEM & 2.45 & 0.66 & 2.44 & 0.87 & 1.97 & 0.69 \\
\hline $650 \mu \mathrm{m}$ & 88.60 & 78.53 & 88.96 & 76.02 & 85.84 & $73.87^{b}$ \\
\hline $850 \mu \mathrm{m}$ & 89.07 & 78.60 & 81.21 & 78.30 & 88.21 & $81.10^{\mathrm{a}}$ \\
\hline SEM & 2.45 & 0.66 & 2.44 & 0.87 & 1.97 & 0.69 \\
\hline Moisture $0.8 \%$ & $84.51^{b}$ & $77.81^{\mathrm{b}}$ & $81.21^{b}$ & $73.87^{b}$ & $83.81^{b}$ & $73.74^{b}$ \\
\hline Moisture 1.6\% & $93.15^{\mathrm{a}}$ & $79.25^{\mathrm{a}}$ & $89.85^{\mathrm{a}}$ & $80.45^{\mathrm{a}}$ & $90.24^{\mathrm{a}}$ & $81.23^{\mathrm{a}}$ \\
\hline SEM & 2.45 & 0.66 & 2.44 & 0.87 & 1.97 & 0.69 \\
\hline \multicolumn{7}{|l|}{ Probabilities } \\
\hline Processing (P) & *2) & ** & * & ** & * & ** \\
\hline Particle size (S) & NS & NS & NS & NS & NS & ** \\
\hline Moisture (M) & * & * & * & * & * & ** \\
\hline$P \times S$ & NS & NS & NS & NS & NS & NS \\
\hline$P \times M$ & NS & NS & NS & NS & NS & NS \\
\hline$S \times M$ & NS & NS & NS & NS & NS & NS \\
\hline CV (\%) & 7.8 & 2.39 & 8.10 & 3.22 & 6.43 & 2.55 \\
\hline
\end{tabular}

SEM, standard error of the mean; CV, coefficient of variation.

1) Each value represents the mean of six replicates.

2) * Significant at $5 \%$; * * Significant at 1\%; NS, not significant.

a,b Means followed by different letters in the column are different by the Tukey test at 5\% probability.

There was a significant interaction between processing and moisture for FI at 21 and 42 days of age (Table 7). When breaking down the interaction, we found that the birds fed expanded feed with $1.6 \%$ moisture had higher FI compared to that with $0.8 \%$ moisture addition at 21 days. However, no difference was observed for the FI of animals fed pelleted feeds prepared with different moisture additions. In contrast, at 42 days of age, we observed that the birds fed pelleted feed with $0.8 \%$ moisture had higher

Table 3. AME and AMEn determined with birds at 10th to 13th day and 27th to 30th day of age fed pelleted and expanded feeds, processed with different particle sizes of ingredients (650×850 microns) and moisture addition levels $(0.8 \% \text { and } 1.6 \%)^{1)}$

\begin{tabular}{|c|c|c|c|c|}
\hline \multirow{2}{*}{ Items } & \multicolumn{2}{|c|}{ AME (kcal/kg) } & \multicolumn{2}{|c|}{ AMEn (kcal/kg) } \\
\hline & 10th - 13th d & 27th - 30th d & 10th - 13th d & 27th - 30th d \\
\hline Expanded & $2,848.97^{b}$ & $2,974.45$ & $2,828.56^{b}$ & $2,963.41$ \\
\hline Pelleted & $2,928.04^{a}$ & $2,954.96$ & $2,908.50^{\mathrm{a}}$ & $2,943.37$ \\
\hline SEM & 23.41 & 34.90 & 23.14 & 34.85 \\
\hline Particle size $650(\mu \mathrm{m})$ & $2,881.19$ & $2,953.07$ & $2,861.44$ & $2,941.29$ \\
\hline Particle size $850(\mu \mathrm{m})$ & $2,895.83$ & $2,976.34$ & $2,875.62$ & $2,965.50$ \\
\hline SEM & 23.41 & 34.90 & 23.14 & 34.85 \\
\hline Moisture $0.8 \%$ & $2,824.21^{b}$ & $2,939.20$ & $2,803.78^{b}$ & $2,927.87$ \\
\hline Moisture 1.6\% & $2,952.80^{\mathrm{a}}$ & $2,990.21$ & $2,933.27^{\mathrm{a}}$ & $2,978.91$ \\
\hline SEM & 23.41 & 34.90 & 23.14 & 34.85 \\
\hline \multicolumn{5}{|l|}{ Probabilities } \\
\hline Processing $(P)$ & *2) & NS & * & NS \\
\hline Particle size (S) & NS & NS & NS & NS \\
\hline Moisture (M) & ** & NS & ** & NS \\
\hline$P \times S$ & NS & NS & NS & NS \\
\hline$P \times M$ & ** & NS & ** & NS \\
\hline $\mathrm{S} \times \mathrm{M}$ & NS & * & NS & * \\
\hline $\mathrm{P} \times \mathrm{S} \times \mathrm{M}$ & NS & NS & NS & NS \\
\hline CV (\%) & 3.97 & 5.77 & 3.95 & 5.78 \\
\hline
\end{tabular}

SEM, standard error of the mean; $\mathrm{CV}$, coefficient of variation.

1) Each value represents the mean of six replicates (fifteen birds per replicate).

2) * Significant at $5 \%$; * Significant at $1 \%$; NS, no significant.

${ }^{a, b}$ Means followed by different letters in the column are different by the Tukey test at $5 \%$ probability. 
Table 4. Breakdown of the processing $\times$ moisture and particle sizexmoisture interactions regarding AME and AMEn of the feeds, determined, respectively, in the birds' initial rearing phase (10 to 13 days old) and growth phase (27 to 30 days old)

\begin{tabular}{|c|c|c|c|c|}
\hline & \multicolumn{2}{|c|}{ AME (kcal/kg) } & \multicolumn{2}{|c|}{ AMEn (kcal/kg) } \\
\hline Moisture (\%) & & 10th & 3th $d$-.. & \\
\hline Processing & 0.8 & 1.6 & 0.8 & 1.6 \\
\hline Expanded & $2,844.71^{\mathrm{Aa}}$ & $2,853.23^{\mathrm{Ba}}$ & $2,824 \cdot 16^{\mathrm{Aa}}$ & $2,832.97^{\mathrm{Ba}}$ \\
\hline Pelleted & $2,803.71^{\mathrm{Ab}}$ & $3,052.37^{\mathrm{Aa}}$ & $2,783.42^{\mathrm{Aa}}$ & $3,033.59^{\mathrm{Aa}}$ \\
\hline SEM & 33.11 & 33.11 & 32.73 & 32.73 \\
\hline Particle size $(\mu \mathrm{m})$ & - & -.--- $27 t$ & Oth $d$-.---.--. & - \\
\hline 650 & $2,871.73^{\mathrm{Ab}}$ & $3,034.40^{\mathrm{Aa}}$ & $2,860.50^{\mathrm{Ab}}$ & $3,022.09^{\mathrm{Aa}}$ \\
\hline 850 & $3,006.66^{\mathrm{Aa}}$ & $2,946.02^{\mathrm{Aa}}$ & $2,995.25^{\mathrm{Aa}}$ & $2,935.75^{\mathrm{Aa}}$ \\
\hline SEM & 49.36 & 49.36 & 49.29 & 49.29 \\
\hline
\end{tabular}

AME, apparent metabolizable energy; AMEn, apparent metabolizable energy corrected to zero nitrogen balance; SEM, standard error of the mean.

$A, B, a, b$ Means followed by different letters, uppercase in the column and lowercase in the row, differ by the Tukey test $(p<0.05)$.

FI while FI of the birds fed expanded feed did not change as a function of moisture addition $(0.8 \%$ and $1.6 \%)$.
There were no effects of the processing methods, particle size and moisture level on carcass, drumstick and abdominal fat yields (Table 8).

\section{DISCUSSION}

Higher pellet quality (pellets, $\%$ and PDI) was obtained in expanded feeds and inclusion of $1.6 \%$ moisture. These results are in accordance with a study of U.S. feed mills, which indicated that feed processed in an expander before pelleting as compared to conventional conditioning-pelleting improved pellet quality [17]. Muramatsu et al [4] reported that conditioner-expander-pelleting treatment and moisture addition up to $21 \mathrm{~g} / \mathrm{kg}$ of feed are effective strategies to enhance pellet quality. Water addition enhanced pellet quality due to its capillary property, which helps to keep particles together [18]. Also, retention of moisture has been linked to an increase in starch gelatinization and improvement in pellet quality [7].

Although coarser particles have resulted in higher PDI in the

Table 5. Coefficients of ileal digestibility of amino acids determined with birds fed pelleted and expanded feeds, processed with different particle sizes of ingredients (650×850 microns) and moisture addition levels $(0.8 \% \text { and } 1.6 \%)^{1)}$

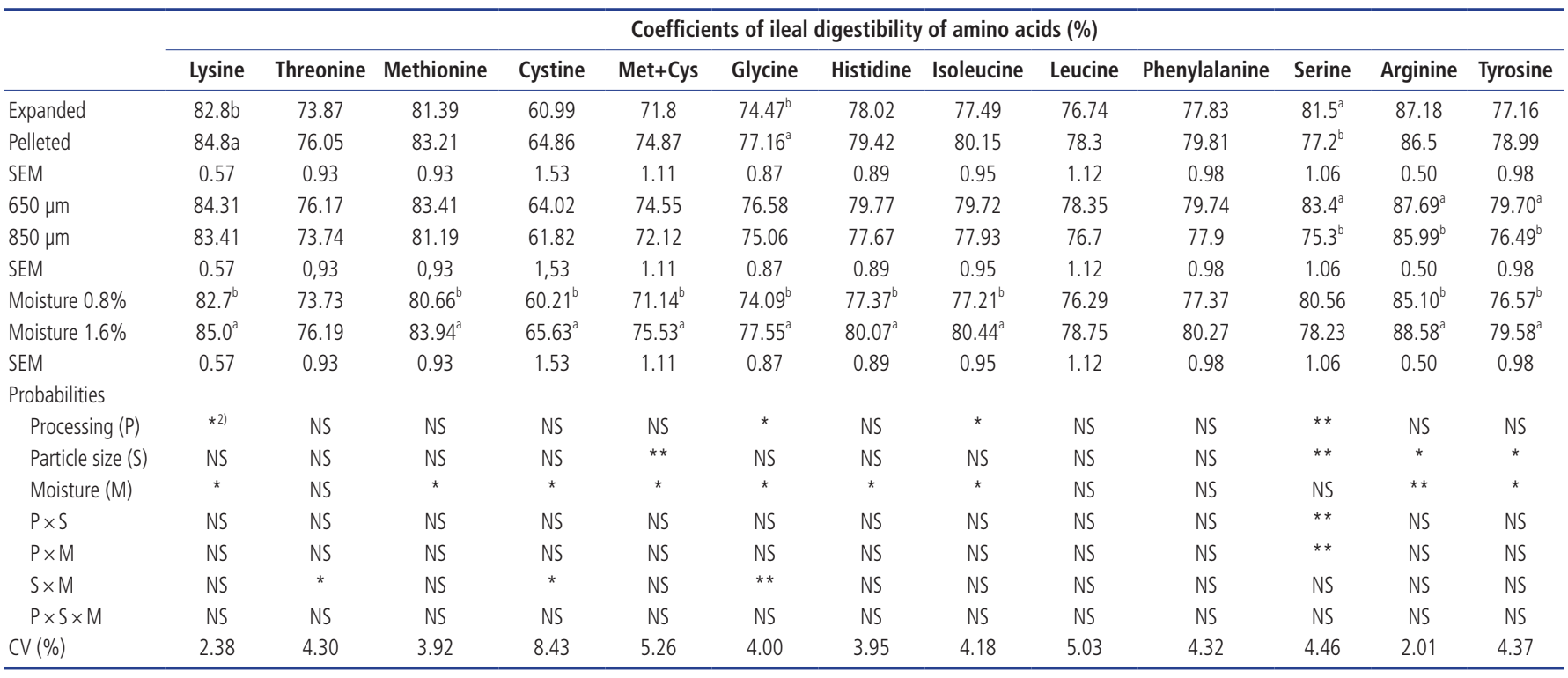

SEM, standard error of the mean; CV, coefficient of variation.

${ }^{1)}$ Each value represents the mean of six replicates (five birds per replicate).

2) * Significant at 5\%; ** Significant at 1\%; NS, not significant.

a,b Means followed by different letters in the column are different by the Tukey test at $5 \%$ probability.

Table 6. Breakdown of moisturexparticle size interaction of ileal digestibility coefficients of amino acids threonine, cystine and glycine

\begin{tabular}{|c|c|c|c|c|c|c|}
\hline \multirow{3}{*}{ Particle size $(\mu \mathrm{m})$} & \multicolumn{6}{|c|}{ Moisture (\%) } \\
\hline & 0.8 & 1.6 & 0.8 & 1.6 & 0.8 & 1.6 \\
\hline & \multicolumn{2}{|c|}{ Threonine } & \multicolumn{2}{|c|}{ Cystine } & \multicolumn{2}{|c|}{ Glycine } \\
\hline 650 & $73.38^{\mathrm{Ab}}$ & $78.97^{\mathrm{Aa}}$ & $58.74^{\mathrm{Ab}}$ & $69.31^{\mathrm{Aa}}$ & $72.82^{\mathrm{Ab}}$ & $80.33^{\mathrm{Aa}}$ \\
\hline 850 & $74.07^{\mathrm{Aa}}$ & $73.41^{\mathrm{Ba}}$ & $61.69^{\mathrm{Aa}}$ & $61.94^{\mathrm{Ba}}$ & $75.35^{\mathrm{Aa}}$ & $74.77^{\mathrm{Ba}}$ \\
\hline SEM & 1.32 & 1.32 & 2.17 & 2.17 & 1.24 & 1.24 \\
\hline
\end{tabular}

SEM, standard error of the mean.

$A, B, a, b$ Means followed by different letters, uppercase in the column and lowercase in the row, differ by the Tukey test $(p<0.05)$. 
Table 7. Performance at 21 and 42 days of age of birds fed pelleted and expanded feeds, processed with different particle sizes of ingredients (650×850 microns) and moisture addition levels $(0.8 \% \text { and } 1.6 \%)^{1)}$

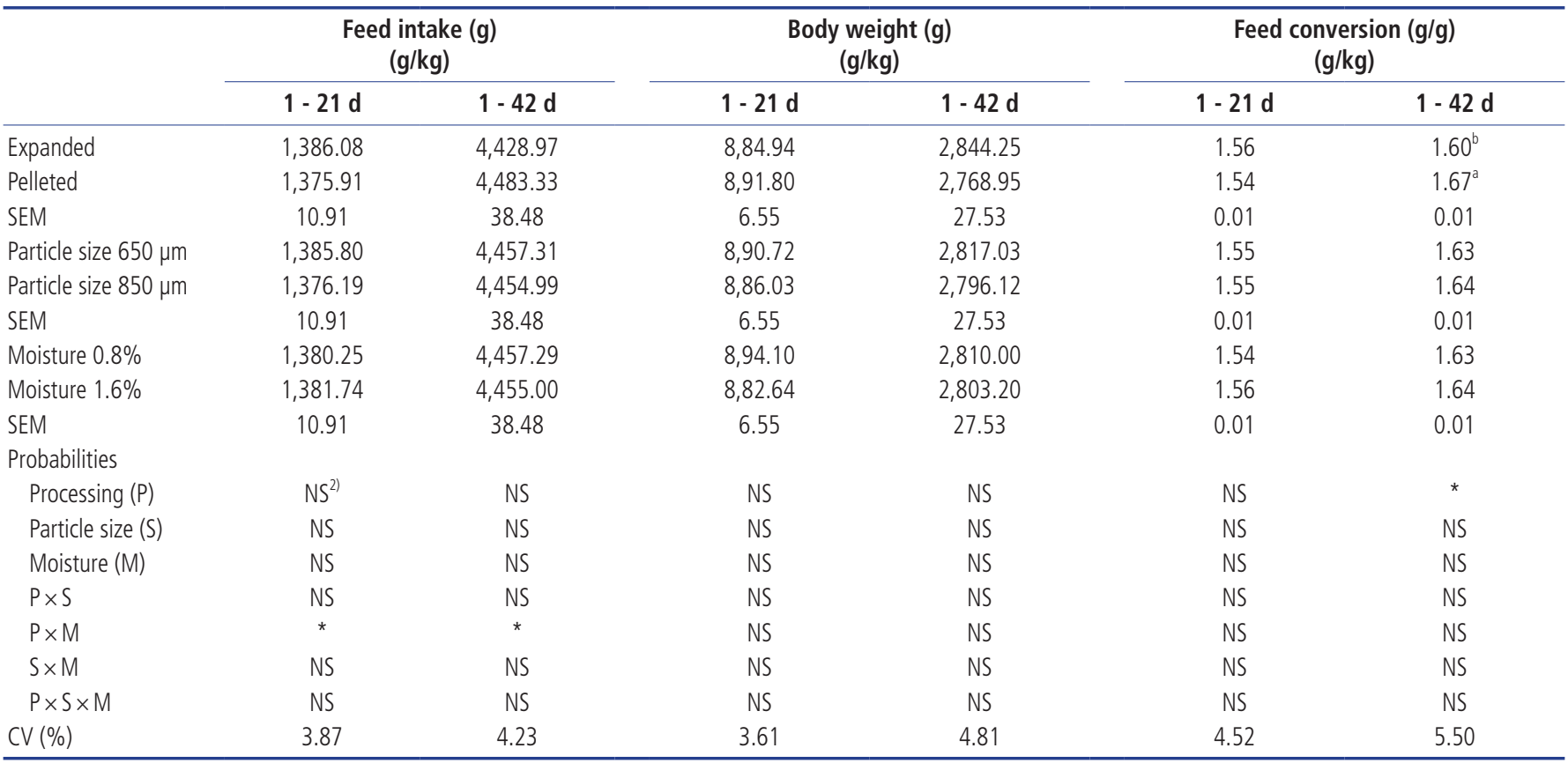

SEM, standard error of the mean.

1) Each value represents the mean of six replicates (fifteen birds per replicate).

2) * Significant at 5\%; NS, not significant.

a,b Means followed by different letters in the column are different by the Tukey test at $5 \%$ probability.

final feeds, it is important to emphasize that use of coarse granulometry in this study agrees with the recommendations in the literature. The use of particles larger than 1,000 or 1,500 microns

Table 8. Carcass yield (\%) and cuts of birds fed pelleted and expanded feeds, processed with different particle sizes of ingredients (650×850 microns) and moisture addition levels $(0.8 \% \text { and } 1.6 \%)^{11}$

\begin{tabular}{lccccc}
\hline & $\begin{array}{c}\text { Carcass } \\
(\%)\end{array}$ & $\begin{array}{c}\text { Brisket } \\
(\%)\end{array}$ & $\begin{array}{c}\text { Thigh } \\
(\%)\end{array}$ & $\begin{array}{c}\text { Drumstick } \\
(\%)\end{array}$ & $\begin{array}{c}\text { Abdominal } \\
\text { fat (\%) }\end{array}$ \\
\hline Expanded & 78.20 & 29.01 & 9.84 & 10.31 & 12.17 \\
Pelleted & 77.98 & 28.07 & 9.90 & 10.54 & 11.68 \\
SEM & 0.30 & 0.44 & 0.09 & 0.08 & 0.36 \\
$650 \mu \mathrm{m}$ & 78.32 & 28.65 & 9.90 & 10.44 & 11.94 \\
$850 \mu \mathrm{m}$ & 77.86 & 28.43 & 9.83 & 10.41 & 11.91 \\
SEM & 0.30 & 0.44 & 0.09 & 0.08 & 0.36 \\
Moisture 0.8\% & 78.12 & 28.84 & 9.90 & 10.44 & 12.12 \\
Moisture 1.6\% & 78.06 & 28.24 & 9.84 & 10.41 & 11.73 \\
SEM & 0.30 & 0.44 & 0.09 & 0.08 & 0.36 \\
Probabilities & & & & & \\
$\quad$ Processing (P) & NS & NS & NS & NS & NS \\
Particle size (S) & NS & NS & NS & NS & NS \\
Moisture (M) & NS & NS & NS & NS & NS \\
P $\times S$ & NS & NS & NS & NS & NS \\
P $\times$ M & NS & NS & NS & NS & NS \\
S $\times$ M & NS & NS & NS & NS & NS \\
CV (\%) & 1.88 & 7.56 & 4.9 & 3.99 & 18.71 \\
\hline
\end{tabular}

SEM, standard error of the mean; CV, coefficient of variation; NS, not significant.

${ }^{1)}$ Each value represents the mean of six replicates (fifteen birds per replicate). can cause fracture of pellets [19]. For this reason, it is recommended that in corn or sorghum-soybean meal feeds for broilers, particle size should be approximately 600 to 900 microns to achieve the highest PDI $[19,20]$.

Unlike for the pellet quality, in the initial rearing phase (10 to 13 days of age) the birds fed pelleted feeds provided AME and AMEn on average $2.8 \%$ higher than obtained for the expanded feeds. The addition of $1.6 \%$ moisture in the mixer provided AME and AMEn values on average $4.6 \%$ higher compared to the use of $0.8 \%$ moisture. According to Buchanan and Moritz [7], the addition of higher levels of water during preparation results in improvements in pellet quality and therefore a greater feed particle hydration. The higher the water absorption index is, the higher the degree of starch gelatinization promoted by thermal processing [21] and the better the results of nutrient utilization expressed by AME and AMEn values.

The reason for higher AME and AMEn values in pelleted feeds prepared with $1.6 \%$ moisture in relation to expanded feeds might derive from the fact that intense food processing increases the Maillard products, reducing protein and starch solubility and digestibility, as described by Zimonja et al [22], Taylor and Dewar [23] and Selle et al [24]. Furthermore, sorghum starch granules are surrounded by a matrix protein layer which can limit enzyme access, decreasing digestibility [25], hindering energy utilization even more of feeds subjected to treatments with high temperatures. Therefore, in this study the temperature of $130^{\circ} \mathrm{C}$ during 
11 seconds to which the expanded feeds were submitted may have been a limiting factor of maximum energy utilization.

The same behavior was observed when assessing the digestibility coefficients of amino acids (DCAA), where the highest efficiency was reached with the use of pelleted feeds prepared with smaller particles (650 microns) and higher moisture amounts (1.6\%).

The advantages observed in thermal processing on the amino acid digestibility can be attributed to protein denaturation, with alterations to three-dimensional structures. The relatively subtle impact of steam-pelletizing on protein digestibility agrees with the position taken by Svihus and Zimonja [26] in their review. Increased enzyme efficiency in protein digestibility and hence of amino acids was also obtained by Surek et al [27] using smaller particle sizes of ingredients.

However, the effects of adding moisture during the thermal processing of the pellets on nutrient digestibility are not clear. According to Buchanan and Moritz [7], increased moisture can interact with other components of the feed, aiding thermomechanical reactions in the pellets. As the temperature increases, the water molecules reach a higher energy state, contributing to destabilize proteins and improve their digestibility. However, severe heating can cause destruction of the primary structure of the proteins and thus break or form some covalent bonds and decrease protein digestibility [26]. The use of high temperature for the expansion of the pellets in this study may have negatively influenced the digestibility of amino acids. Similar to these results, [28] observed that moderate temperatures and short treatment times showed no effects on amino acid availability, but intensive heat treatment significantly reduced amino acid availability. Boroojeni et al [29] also observed negative effect on ileal digestibility of amino acids in broilers by raising the long-term conditioning temperature (pelleted feeds at $85^{\circ} \mathrm{C}$ for $3 \mathrm{~min}$ ).

There was no effect of feed processing on the birds weigh gain. However, unlike the results observed in this study, Lundblad et al [30] found higher weigh gains in broilers fed expanded feeds when compared to pellets. Although with lower values of AME and DCAA in the starter phase, we observed improved FC at 42 days in birds fed expanded feeds in relation to pelleted feeds.

Abdollahi et al [31] and Abdollahi et al [32] showed that although increasing conditioning temperatures above $60^{\circ} \mathrm{C}$ or $90^{\circ} \mathrm{C}$ negatively affected the nutrient utilization, the better pellet quality obtained in feeds processed at these temperatures restored the performance of broilers. According to the authors, the magnitude of the body weigh gain and FI responses of broilers fed pellet feeds reflect a balance between the negative effect of conditioning at higher temperatures on nutrient availability and the positive effect on pellet quality. In general, the effect of thermal treatment on better feed efficiency is partly due to the fact the higher proportion of whole pellets facilitates broiler FI and decreases feed waste, thereby reducing feed energy used for maintenance [33].

The particle size did not affect broiler performance in any of the assessed age ranges. Similar results were described by Zang et al [34], who found no difference in FI, WG, and FC when studying pelleted feeds with particle sizes of 953 and 597 microns. Similarly, Boroojeni et al [29], when comparing feeds prepared by different processes, conditioning temperatures and organic acids addition (pelletized at $70^{\circ} \mathrm{C}$, pelletized at $85^{\circ} \mathrm{C}$ for $3 \mathrm{~min}$, and expanded at $110^{\circ} \mathrm{C}$ or $130^{\circ} \mathrm{C}$ from 3 to 5 seconds) did not observe changes in broiler performance.

Pelleted diets prepared with a milling particle size of $650 \mathrm{mi}-$ crons and $1.6 \%$ moisture provided increased ileal digestibility of amino acids and AMEn in the tarter period. However, the expanded feeds improved pellet quality and feed conversion of broilers at 42 days of age. We conclude that factors such as moisture, particle size and processing affect the pellet quality, and therefore should be considered when attempting to optimize broiler performance.

\section{CONFLICT OF INTEREST}

We certify that there is no conflict of interest with any financial organization regarding the material discussed in the manuscript.

\section{ACKNOWLEDGMENTS}

We are grateful to the company Brasil Foods for supporting this research and to the National Council for Scientific and Technological Development (CNPq) for the financial support (process number 487959/2013-2).

\section{REFERENCES}

1.Abdollahi, MR, Ravindran V, Wester TJ, Ravindran G, Thomas DV. Influence of conditioning temperature on performance, apparent metabolisable energy, ileal digestibility of starch and nitrogen and the quality of pellets, in broiler starters fed maize-and sorghum-based diets. Anim Feed Sci Technol 2010;162:106-15.

2.López CAA, Baião NC, Lara LJC, Rodriguez NM, Cançado SV. Effects of physical form of ration on feed digestibility and performance of broiler chickens. Arq Bras Med Vet Zootec 2007;59;1006-13.

3.Nir I, Shefet G, Aroni Y. Effect of particle size on performance. 1. Corn. Poult Sci 1994;73:45-9.

4.Muramatsu K, Maiorka A, Vaccari ICM, et al. Impact of particle size, thermal processing, fat inclusion and moisture addition on pellet quality and protein solubility of broiler feeds. J Agric Sci Technol 2014;16:1017-28.

5.Chewning CG, Stark CR, Brake J. Effects of particle size and feed form on broiler performance. J Appl Poult Res 2012;21:830-7.

6.Thomas M, Van Der Poel AFB. Physical quality of pelleted animal feed 1. Criteria for pellet quality. Anim Feed Sci Technol 1996;61: 89-112.

7.Buchanan NP, Moritz JS. Main effects and interactions of varying formulation protein, fiber, and moisture on feed manufacture and 
pellet quality. J Appl Poult Res 2009;18:274-83.

8.Test Sieving: Principles and Procedures [Internet]. Advantech Manufacturing, Inc.; 2001 [cited 2017 july 19]. Avaliable from http://www. espanol-advantechmfg.com/pdf/principles_procedures_manual_ with_tables-2.pdf

9.Froetschner, J. Conditioning controls quality of pellet. Feed Tech 2006;10:12-5.

10. Löwe, R. Judging pellet stability as part of pellet quality. Feed Tech 2005;9:15-9.

11. Matterson LD, Potter LM, Stutz MW, Singsen EP. The metabolizable energy of feed ingredients for chickens. Storrs, CT, USA: The University of Connecticut, Agricultural Experiment Station; 1965. p. 11. Research Report. 7.

12. Sakomura NK, Rostagno HS. Research methods in monogastric nutrition. 2th ed. Jaboticabal, SP, Brazil: Funep; 2016. p. 282.

13. Scott TA, Boldaji F. Comparison of inert markers (chormic oxide or insoluble ash [CeliteTM]) for determining apparent metabolizable energy of wheat-or barley-based broiler diets with or without enzymes. Poult Sci 1997;76:594-8.

14. Detmann E, Souza MA, Valadares Filho SC et al. Métodos para análise de alimentos. Visconde do Rio Branco, Brazil: Suprema; 2012.

15. Santos FR, Hruby M, Pierson EEM, Remus JC, Sakomura NK. Effect of phytase supplementation in diets on nutrient digestibility and performance in broiler chicks. J Appl Poult Res 2008;17:191-201.

16. Ferreira DF. 2014. Sisvar: a guide for its Bootstrap procedures in multiple comparisons. Ciênc Agrotec 2014;38:109-12.

17. Parsons AS, Buchanan NP, Blemings KP, Wilson ME, Moritz JS. Effect of corn particle size and pellet texture on broiler performance in the growing phase. J Appl Poult Res 2006;15:245-55.

18. Thomas M, Van der Poe. Physical quality of pelleted animal feed 1 . Criteria for pellet quality. Anim Feed Sci Technol 1996;61:89-112.

19. Franke M, Rey A. Improving pellet quality and efficiency. Feed Tech 2006;10:5-12.

20. Amerah AM, Ravindran V, Lentle RG, Thomas DG. Feed particle size: implications on the digestion and performance of poultry. World's Poult Sci J 2007;63:439-51.

21. Plavnik I, Sklan D. Nutritional effects of expansion and short time extrusion on feeds for broilers. Anim Feed Sci Technol 1995;55:24751.

22. Zimonja O, Hetland H, Lazarevic N, Edvardsen DH, Svihus B. Effects of fibre content in pelleted wheat and oat diets on technical pellet quality and nutritional value for broiler chickens. Can J Anim Sci
2008;88:613-22.

23. Taylor JRN, Dewar J. Developments in sorghum food technologies. Adv Food Nutr Res 2001;43:217-64.

24. Selle PH, Cadogan DJ, Li X, Bryden WL. Implications of sorghum in broiler chicken nutrition. Anim Feed Sci Technol 2010;156:57-74.

25. Bryden WL, Li X, Ravindran G, Ll H, Ravindran V. Ileal digestible amino acid values in feedstuffs for poultry. RIRDC; 2009. no. 09/071. p. 76.

26. Svihus B, Zimonja O. Chemical alterations with nutritional consequences due to pelleting animal feeds: a review. Anim Prod Sci 2011; 51:590-6.

27. Surek D, Maiorka A, Dalke F, et al. Phytase use in diet with different particle size for broiler chicken at initial stage. Ciênc Rural 2008;38: 1725-9.

28. Amezcua CM, Parsons CM. Effect of increased heat processing and particle size on phosphorus bioavailability in corn distillers dried grains with solubles. Poult Sci 2007;86:331-7.

29. Boroojeni FG, Mader A, Knorr F, et al. The effects of different thermal treatments and organic acid levels on nutrient digestibility in broilers. Poult Sci 2014;93:1159-71.

30. Lundblad KK, Hancock JD, Behnke KC, et al. The effect of adding water into the mixer on pelleting efficiency and pellet quality in diets for finishing pigs without and with use of an expander. Anim Feed Sci Technol 2009;150:295-302.

31. Abdollahi MR, Ravindran V, Wester TJ, Ravindran G, Thomas DV. Influence of feed form and conditioning temperature on performance, apparent metabolisable energy and ileal digestibility of starch and nitrogen in broiler starters fed wheat-based diet. Anim Feed Sci Technol 2011;168:88-99.

32. Abdollahi MR, Ravindran V, Wester TJ, Ravindran G, Thomas DV. Effect of improved pellet quality from the addition of a pellet binder and/or moisture to a wheat-based diet conditioned at two different temperatures on performance, apparent metabolisable energy and ileal digestibility of starch and nitrogen in broilers. Anim Feed Sci Technol 2012;175:150-7.

33. Abdollahi MR, Ravindran AV, Svihus B. Pelleting of broiler diets: An overview with emphasis on pellet quality and nutritional value. Anim Feed Sci Technol 2013;179:1-23.

34. Zang JJ, Piao XS, Huang DS, et al. Effects of feed particle size and feed form on growth performance, nutrient metabolizability and intestinal morphology in broiler chickens. Asian-Australas J Anim Sci 2009;22: 107-12. 